\title{
Laser Deposition of Tetrasulfonated Phthalocyanine Layers for Gas Sensors
}

\author{
Premysl Fitl ${ }^{1}$, Martin Vrnata ${ }^{1}$, Dusan Kopecky ${ }^{1}$, Jan Vlcek ${ }^{1}$, Jitka Skodova ${ }^{1}$, \\ Jaroslav Hofmann ${ }^{1}$, Vladimir Myslik ${ }^{2}$ \\ ${ }^{1}$ Department of Physics and Measurement, Institute of Chemical Technology, Technicka 5, Prague 6, CZ - 166 28, Czech Republic \\ ${ }^{2}$ Department of Solid-State Engineering, Institute of Chemical Technology, Technicka 5, Prague 6, CZ - 166 28, Czech Republic \\ Email: martin.vrnata@vscht.cz
}

Received 2012

\begin{abstract}
Thin layers of nickel and copper tetrasulfonated phthalocyanines (NiPcTS and CuPcTS) were prepared by Matrix Assisted Pulsed Laser Evaporation method. The depositions were carried out with $\mathrm{KrF}$ excimer laser (energy density of laser radiation $E_{\mathrm{L}}=0.1$ to 0.5

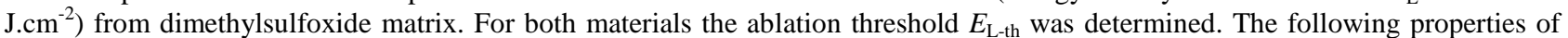
deposited layers were characterized: a) chemical composition (FTIR spectra); b) morphology (SEM and AFM portraits); c) impedance of gas sensors based on NiPcTS and CuPcTS layers in the presence of two analytes - hydrogen and ozone. The prepared sensors exhibit response to $1000 \mathrm{ppm}$ of hydrogen and $100 \mathrm{ppb}$ of ozone even at laboratory temperature.
\end{abstract}

Keywords: Matrix Assisted Pulsed Laser Evaporation; Substituted Phthalocyanines; Gas Sensors; Impedance Measurement

\section{Introduction}

Matrix Assisted Pulsed Laser Evaporation (MAPLE), introduced by Piqué et al. in 1999, is one of the experimental laser deposition methods used for deposition of thin uniform films of organic [1] and even biological materials [2].

MAPLE is characterized by indirect contact of the laser radiation with deposited material. The target used for MAPLE consists of two substances; each has a different function during the deposition process. The first one is the deposited material itself, the second is a matrix, which has majority representation (approximately $95 \%$ of target) and has usually a character of low molecular weight volatile solvent of the deposited material. Both substances are mixed together and frozen to liquid nitrogen temperature to suppress sublimation of the matrix at low temperature. In case of correct setting of the deposition conditions, all the energy of laser pulse is absorbed by matrix. The matrix has two functions: i) it protects the environment of a fragile deposited material from high-energy laser radiation and ii) serves as an energy transmitter from electromagnetic radiation to kinetic energy of the molecular oscillation motion, which causes ablation of a deposited material to a plasma state and its subsequent deposition. Selection of a suitable matrix is therefore essential for successful and non-destructive deposition of a material.

The mechanism of MAPLE deposition is shown in Figure 1. Frozen target is placed in a vacuum and impinged by pulses of laser radiation, whose energy is absorbed preferentially by the matrix, which leads to local overheating of the frozen target, followed by abrupt release of the matrix - so-called surface ablation of target. Through collective collisions, matrix molecules pull the molecules of the deposited material and impart them sufficient kinetic energy required to overcome the target-substrate distance. Large molecules of the deposited ma- terial have lower vapor pressure than volatile small molecules of matrix and therefore they are less often pumped away by vacuum system; so the substrate is gradually covered with a thin layer of deposited material with minimum content of matrix molecules.

The most significant group of chemical gas sensors operates on the basis of ability of thin semiconductive layers (=sensitive layers) to chemisorb various gaseous analytes on their surfaces with subsequent exchange of electrons between analyte and sensitive layer [3]. While reducing gases posses ability to act as electron donors, the oxidizing ones are electron acceptors, i.e. they extract electrons from the sensitive layer. At present, some classes of organic substances (conducting polymers [4], complexes of organic ligands with metallic cation [5] etc.) are intensively investigated as prospective materials for sensitive layers. In general, the suitable materials can be characterized as organic molecules containing conjugated system of double bonds,

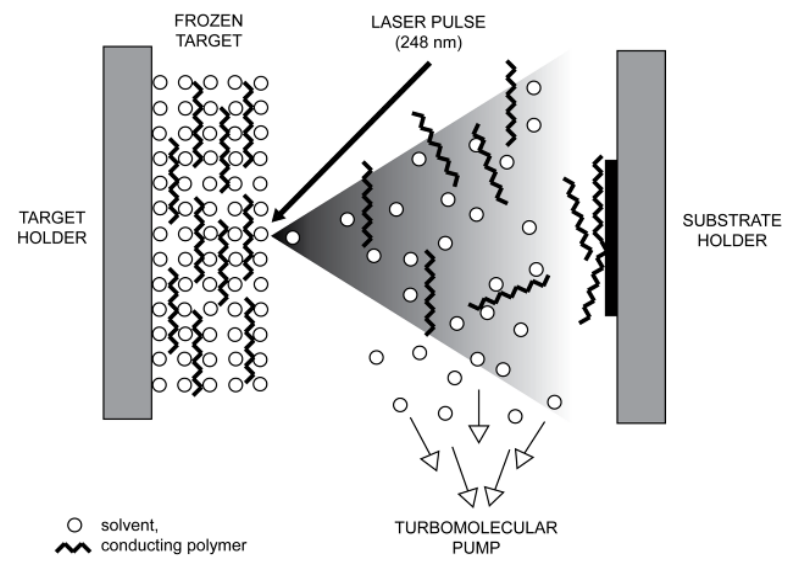

Figure 1. Principle of MAPLE method. 
where $\pi$-electrons form delocalised and highly polarizable system which exhibits ability to enter reversible interaction with the analyte.

Among organocomplexes, both phthalocyanines and substituted phthalocyanines are known to be excellent materials for gas sensing [6,7]. However, when one selects proper method for depositing sensitive layer, there is a significant difference between them: while phthalocyanines are almost insoluble in all solvents, some of their substituted derivatives exhibit a good solubility in low molecular solvents. Due to this fact substituted phthalocyanines (unlike non-substituted ones) can be deposited by MAPLE method.

The presented paper deals with preparation of gas sensor sensitive layers based on tetrasulfonated phthalocyanines (NiPcTS and CuPcTS). The depositions were carried out from dimethylsulfoxide matrix by MAPLE method, providing tool for gentle, non-destructive and easily adjustable grown of organic materials. Responses of prepared sensors to hydrogen and ozone are also presented.

\section{Experimental}

\subsection{Deposition of NiPcTS and CuPcTS thin Layers by MAPLE Method}

In our experiments MAPLE instrumentation was carried out as follows: Powder of NiPcTS or CuPcTS (Sigma-Aldrich) was diluted in dimethylsulfoxide matrix to obtain solution containing 0.2 weight\%. Dimethylsulfoxide matrix was recently proved to be proper for depositions with $\mathrm{KrF}$ excimer laser [8]. After sonification the resulting solution was filtered and then frozen by liquid nitrogen. The freezing process proceeded in a tubular mould so as to produce targets for MAPLE in the form of tablets (approx. $40 \mathrm{~mm}$ in diameter and $10 \mathrm{~mm}$ thick). Then the deposition conditions were set (KrF excimer laser operating at $248 \mathrm{~nm}$; energy density of laser radiation $E_{\mathrm{L}}$ ranging from 0.1 to $0.5 \mathrm{~J} . \mathrm{cm}^{-2}$; repetition rate of laser pulses $f_{\text {rep }}=10 \mathrm{~Hz}$, pulse duration 15 ns; residual pressure in the deposition chamber $10^{-4}$ $\mathrm{Pa}$; working atmosphere during depositions was $3 \mathrm{~Pa}$ of nitrogen; target-substrate distance $35 \mathrm{~mm}$ ).

\subsection{Characterization of Chemical Composition and Morphology of the Layers}

Chemical composition of the deposited layers was analyzed from the IR spectra scanned by the Attenuated Total Reflection Fourier Transform Infrared spectroscopy (ATR FTIR). The spectra were scanned using a BRUKER IFS $66 \mathrm{~V}$ device (diamond crystal) in the interval of wavenumbers from 600 to $1800 \mathrm{~cm}^{-1}$ covering finger-print of MePcTS molecules.

The surface morphology of the samples deposited on polished silicon wafer was acquired using Atomic Force Microscopy (AFM). The AFM images were taken on Veeco Digital Instruments CP II apparatus. For sample characterization, 'Tapping mode' rather than 'Contact mode' was chosen to minimize damage to the sample surfaces. A Veeco oxide-sharpened silicon probe RTESPA-CP attached to a flexible microcantilever was used at its resonant frequency of $300 \mathrm{kHz}$. The image resolution was $256 \times 256$ pixels. Layers morphology was further characterized by Scanning Electron Microscopy (SEM) with
JEOL JSM-7500F instrument.

\subsection{Measuring of Gas Sensor Response}

In order to test gas sensing properties the layers were deposited onto alumina sensors substrates $\left(2.0 \times 2.5 \mathrm{~mm}^{2}\right)$ equipped with interdigital electrodes (Figure 2). The sensor impedance was measured in "pure" synthetic air (as a reference atmosphere) and in synthetic air containing $1000 \mathrm{ppm}$ of hydrogen or 100 ppb of ozone respectively. The impedance measurements were performed with a HP4192LF impedance analyser with frequency of testing signal from $15 \mathrm{~Hz}$ to $10 \mathrm{MHz}$ and amplitude remained constant at $100 \mathrm{mV}$. The obtained data were represented as Nyquist diagrams - i.e. they are plotted as imaginary part of complex impedance vs. real part of complex impedance with frequency of testing signal as a parameter. From Nyquist diagrams the so called phase-angle sensitivity $S_{\mathrm{pa}}$ [deg.] of sensors was evaluated. The detailed definiton of $S_{\mathrm{pa}}$ is in $[9,10]$ and see also Figure 3.
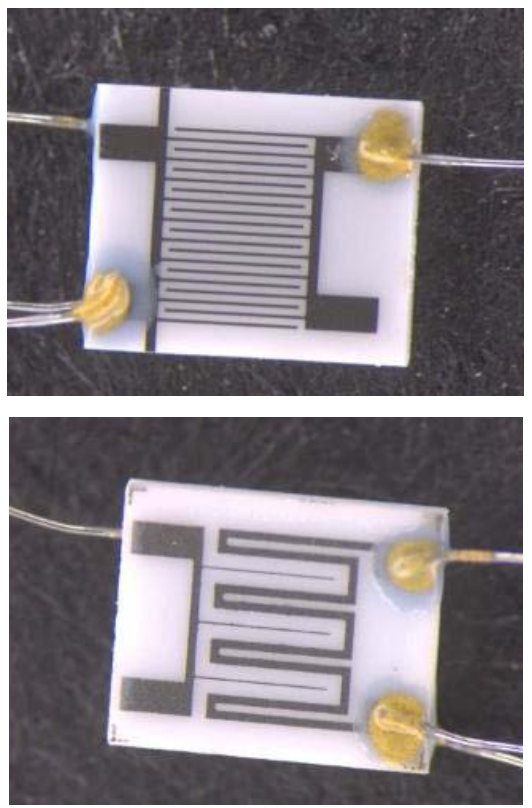

Figure 2. Sensor substrate - front side with interdigital electrodes (left); back side with resistance heating (right).

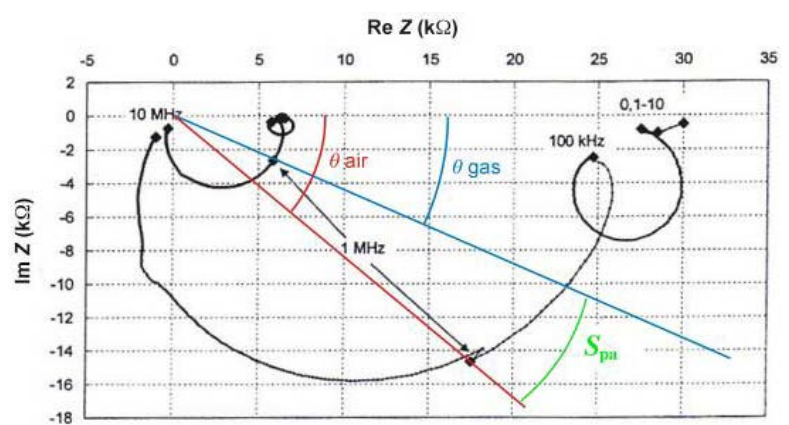

Figure 3. A typical Nyquist diagram of gas sensor with MePcTS sensitive layer in synthetic air (reference) and measured gas (1000 ppm of hydrogen). In this example phase-angle sensitivity $S_{\mathrm{pa}}$ is evaluated as a difference of sensor impedance arguments ( $\theta$ angle) for $1 \mathrm{MHz}$ frequency of testing signal. 


\section{Results and Discussion}

\subsection{Determination of Ablation Threshold}

The depositions made by $\mathrm{KrF}$ laser in the range of energy density of laser radiation from 0.1 to $0.6 \cdot \mathrm{dm}^{-2}$ can be assembled into a dependence of growth rate on laser fluence, known as the ablation curve (Figure 4). On basis of these curves, the ablation thresholds $E_{\mathrm{L} \text {-th }}$ were determined to be $E_{\mathrm{L}-\mathrm{th}} \sim 0.2 \mathrm{Jcm}^{-2}$ for NiPcTS and $E_{\mathrm{L}-\mathrm{th}} \sim 0.3 \mathrm{Jcm}^{-2}$ for CuPcTS. Ablation threshold is a parameter important from the practical point of view, as it corresponds to energy density sufficient for effective layer grown on one side, while there is no excessive photo- and heatstress of deposited material on the other side.

\subsection{FTIR Spectra of Source Substances and Deposited Layers}

Infrared spectra of source substances were compared to those of deposited materials (Figures 5(a),(b) and Figures 6(a), (b) in order to evaluate the degree of material decomposition during MAPLE process. Both materials were deposited at energy densities corresponding to their ablation threshold. Analyzing spectra of source materials (Figures 5(a) and 6(a)) one may notice that absorbtion bands are rather wide. This phenomenon can be attributed to occurrence of traces of mono-, di- and tri- sulfonated phthalocyanines in commercially distributed metal tetrasulfonated phthalocyanines (MePcTS). Nevertheless, it is apparent, that in both cases the transfer of material by MAPLE method was nondestructive, as the positions and in most cases also amplitudes of absorbtion maxima are retained when comparing Figure 5(a) with (b) or Figures 6(a) with (b). An overview of absorption bands of phthalocyanines is summarized in [11].
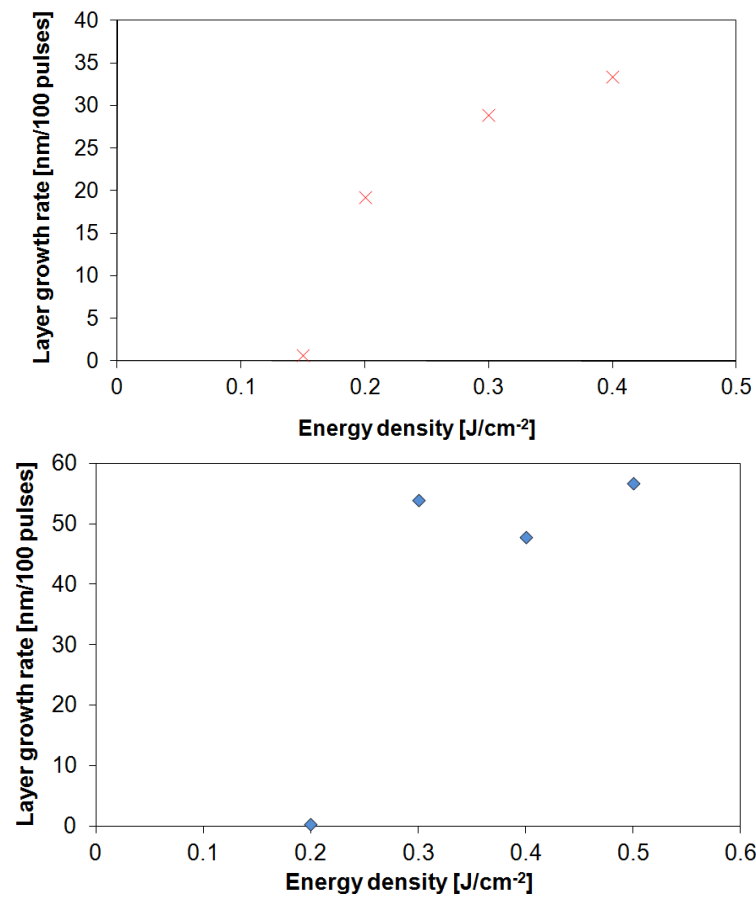

Figure 4. Ablation curves for NiPcTS (top) and CuPcTS (bottom).

\subsection{Layers Morphology}

The layers deposited at ablation thresholds were also studied by SEM (Figure 7) and AFM (Figure 8) methods. The portraits resulting from these methods reveal that the structure of MAPLE deposited layer is rather segmented with large relative surface; these properties are favourable for applications in gas sensing (the detection process is localized on the surface of sensitive layer).

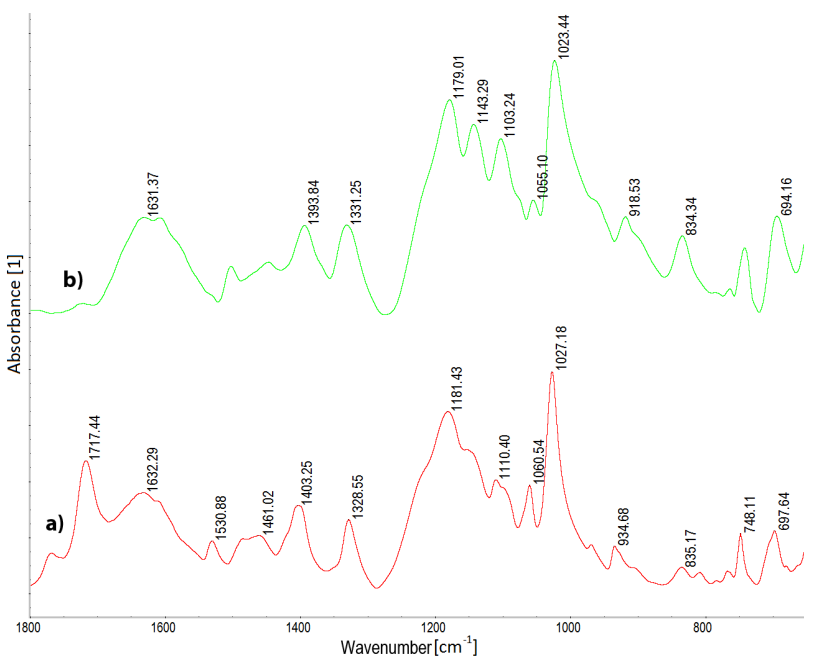

Figure 5. FTIR spectrum of NiPcTS: source material (a); layer deposited at $E_{\mathrm{L} \text {-th }}=0.2 \mathrm{~J} \cdot \mathrm{cm}^{-2}$ (b).

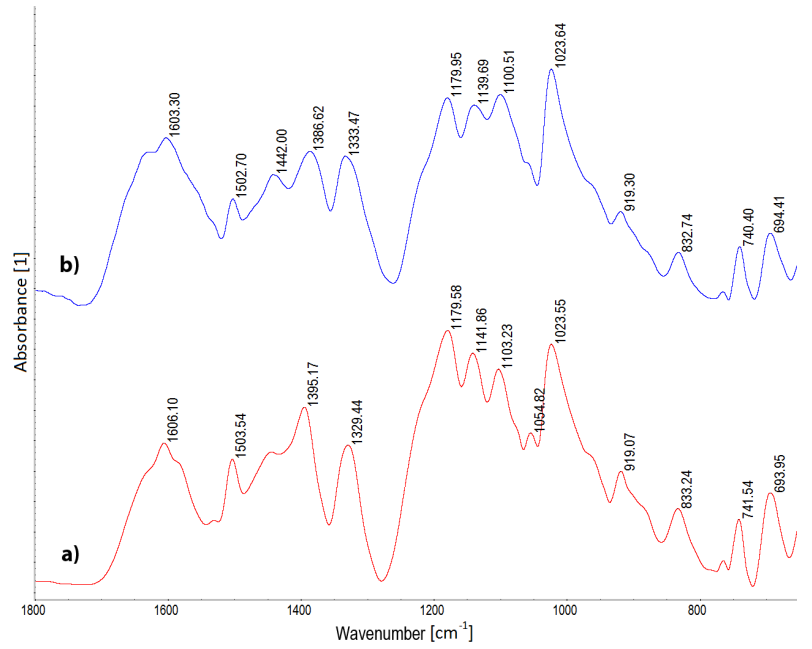

Figure 6. FTIR spectrum of CuPcTS: source material (a); layer deposited at $E_{\mathrm{L} \text {-th }}=0.3 \mathrm{~J} \cdot \mathrm{cm}^{-2}$ (b).
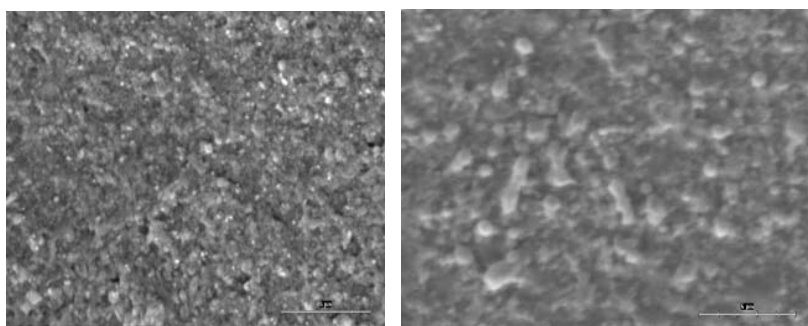

Figure 7. SEM portraits of NiPcTS (left) and CuPcTS (right). 


\subsection{Impedance Measurements and Phase-Angle Sensitivity}

The NiPcTS and CuPcTS layers were deposited to sensor substrates, the impedance of obtained structures was measured and phase-angle $\left(S_{\mathrm{pa}}\right)$ sensitivity to $1000 \mathrm{ppm}$ of hydrogen and 100 ppb of ozone evaluated. The results are summarized in sequention of Figures 9-12.

The sensors exhibit the highest phase-angle sensitivity $\left(S_{\mathrm{pa}}\right.$ ranging from 5 to $12 \mathrm{deg}$ ) at approx. $500 \mathrm{kHz}$ frequency of measuring signal in all cases. CuPcTS sensors have also secondary maximum in the vicinity of $100 \mathrm{~Hz}$. As for temperature dependence of $S_{\mathrm{pa}}$ - the sensors were tested at operating temperatures $25-90^{\circ} \mathrm{C}$, because at higher temperatures reaction of MePcTS with atmospheric oxygen can start. There was also found certain low-temperature sensitivity - i.e. measurable sensor response at $25^{\circ} \mathrm{C}$.
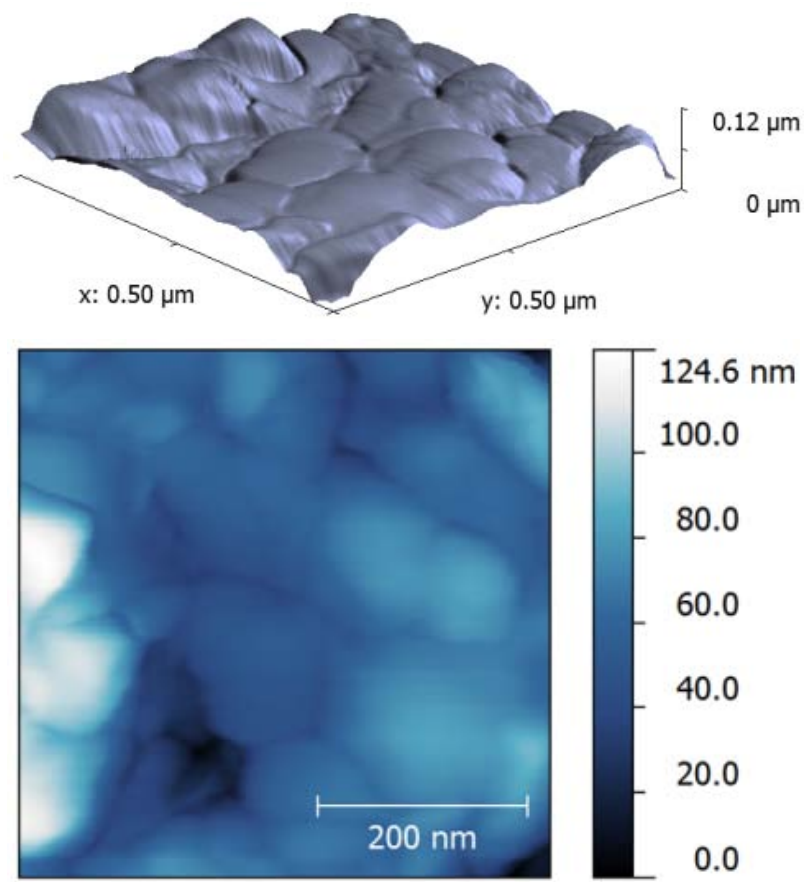

$124.6 \mathrm{~nm}$ 100.0

80.0

60.0

40.0

20.0

0.0

Figure 8. AFM portrait of NiPcTS.

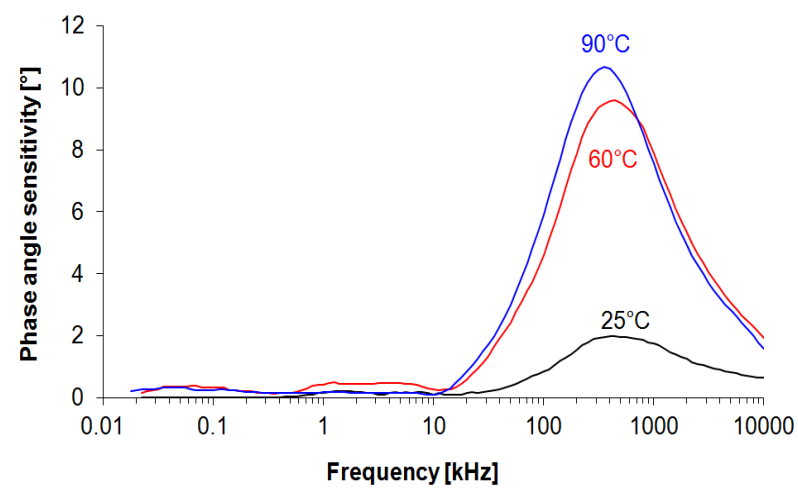

Figure 9. Phase-angle sensitivity of NiPcTS to $1000 \mathrm{ppm}$ of hydrogen.

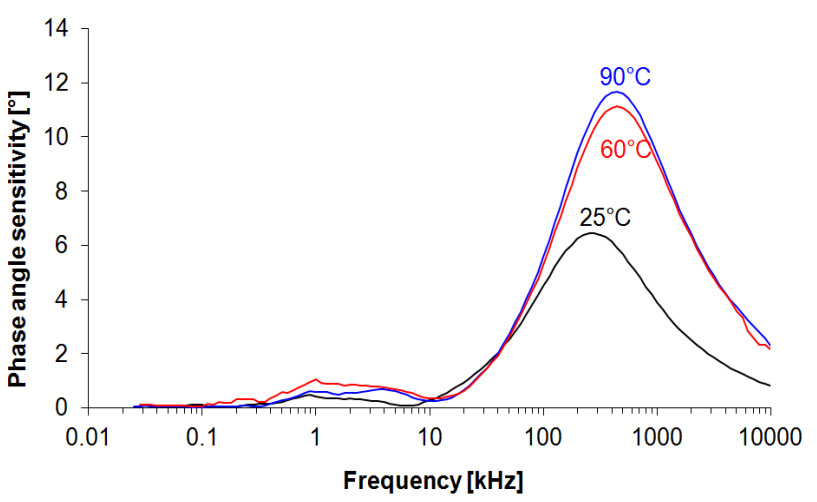

Figure 10. Phase-angle sensitivity of NiPcTS to $100 \mathrm{ppb}$ of ozone.

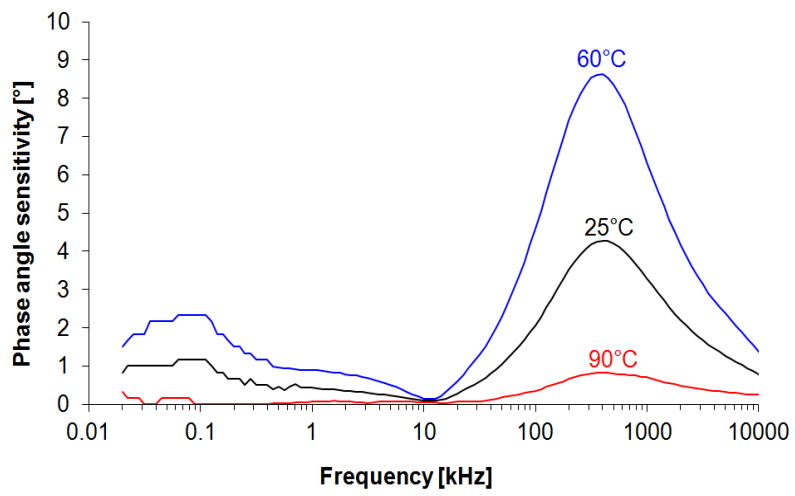

Figure 11. Phase-angle sensitivity of CuPcTS to 1000 ppm of hydrogen.

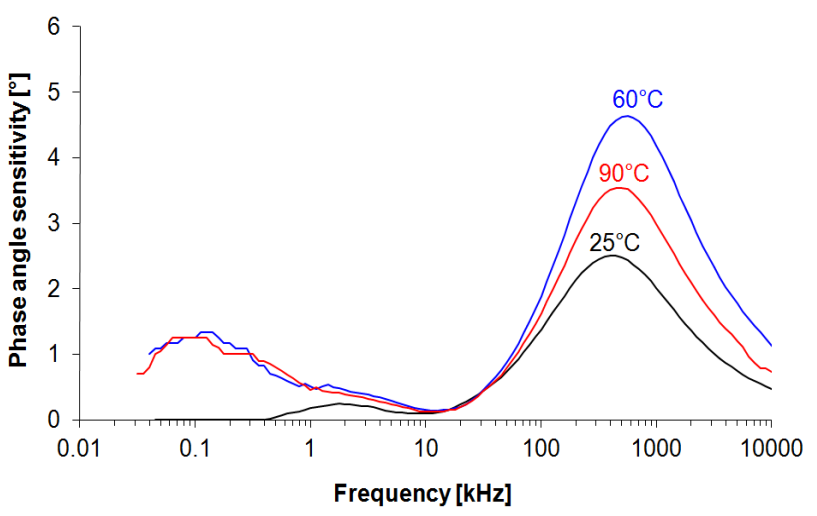

Figure 12. Phase-angle sensitivity of CuPcTS to $100 \mathrm{ppb}$ of ozone.

\section{Conclusions}

Tetrasulfonated metal phthalocyanines were deposited by MAPLE method from dimethylsulfoxide matrix. It was proved that for energy density of laser radiation corresponding to ablation threshold the molecular structure of MePcTS remained preserved. The prepared layers have porous structure with large relative surface -properties suitable for sensor applications. The sensors based on deposited layers were successfully tested for detection of hydrogen and ozone; low temperature sensitivity was observed, hence these sensors are able to operate at laboratory temperature . 


\section{Acknowledgements}

This work was supported by Grant Agency of the Czech Republic (GAČR) projects No. P108/11/1298 and P108/12/P802 and also financial support from specific university research (MSMT No. 21/2012).

\section{REFERENCES}

[1] A. Piqué, R.A. McGill and D.B.Chrisey, "Growth of organic thin films by the matrix assisted pulsed laser evaporation (MAPLE) technique,” Thin Solid Films, vols. 355-356, pp. 536-541, 1999.

[2] D.B. Chrisey, A. Piqué and R.A. McGill, "Laser deposition of polymer and biomaterial films," Chem. Rev., vol. 103, pp. 553-576, 2003.

[3] W. Göppel and K. D. Schierbaum, " $\mathrm{SnO}_{2}$ sensors: current status and future prospects,” Sens. Actuators B, vol. 26/27, pp. 1-12, 1995.

[4] S. Carquigny, "Ammonia gas sensor based on electrosynthesized polypyrrole films,” Talanta, vol. 78, pp. 199-206, 2009.

[5] D. Delmare and C. Bied-Charreton, "Grafting of cobalt porphy- rins in sol-gel matrices:application to the detection of amines," Sens.Actuators B, vol. 62, pp.136-142, 2000.

[6] S. Nespurek, "Soluble phthalocyanines: Perspective materials for electronics,” Mol. Liq. Cryst., vol. 468, pp. 355-373, 2007.

[7] Y.Q. Chen, W.M. Zhang and G.A. Li, "Saw gas sensor with copper tetrasulfonated phthalocyanine film," Sens. Actuators B, vol. 20, pp. 247-249, 1994.

[8] R. Fryček, F.Vysloužil, V. Myslík, M.Vrňata, D. Kopecký, O. Ekrt, P. Fitl, M.Jelínek, T. Kocourek and R. Šipula, "Deposition of organic metalocomplexes for sensor applications by MAPLE," Sens. Actuators B, vol. 125, pp. 189-1949, 2007.

[9] V. Myslík, F.Vysloužil, M. Vrňata, Z. Rozehnal, M. Jelínek, R. Fryček and M. Kovanda, "Phase ac-sensitivity of oxidic and acetylacetonic gas sensors," Sens. Actuators B, vol. 89, pp. 205-211, 2003.

[10] P. Fitl, V. Myslík, M. Vrňata, J. Náhlík, D. Kopecký, J. Vlček, J. Hofmann, J. Lančok, "Sensing properties of tin acetylacetonate-based thin films doped with platinum," Sens. Mater., vol.24, pp. 75-86, 2012.

[11] M. Fukui, "Structural characterization of phthalocyanine Langmuir-Blodgett multilayer assemblies by ft-ir spectroscopy," Chem. Phys. Lett., vol. 177, pp. 247-251, 1991. 